\title{
CAŁA WŁADZA W RECCE RAD? O FORMACH DEMOKRATYCZNEJ KONTROLI NAD WYTWARZANIEM KULTURY*
}

\begin{abstract}
Tekst ten dedykuję pamięci Rafała Górskiego (1973-2010) — działacza społecznego, mojego przyjaciela, dobrego człowieka
\end{abstract}

\section{ZAGADKA DAMIENA HIRSTA}

Chciałbym zacząć od uściślenia terminologicznego. Pojęcia „kultura” będę tu używał tylko w wąskim sensie - mam na myśli wytwory symboliczne, które mogą być poddawane osądowi artystycznemu lub estetycznemu - a nie w znaczeniu szerszym, tożsamym z pojęciem „cywilizacja” (całościowy sposób życia jakiegoś społeczeństwa) ${ }^{1}$. Warto to dookreślić, ponieważ żyjemy w epoce, w której kultura również w sensie całościowego sposobu życia zaczęła być wytwarzana celowo i na szeroką skalę. Chodzi mi o zjawisko kultury masowej, obejmujące utowarowienie nie tylko kultury w wąskim znaczeniu - co zdiagnozowali dobre kilka dekad temu badacze ze szkoły frankfurckiej, w tym przede wszystkim Theodor Adorno, autor terminu „przemysły kultury” — ale również stylu życia. Proces ten opisał amerykański historyk i socjolog Thomas Frank w znakomitej książce The Conquest of $\mathrm{Cool}^{2}$.

Adres do korespondencji: jan.sowa@uj.edu.pl

* Tekst napisany na podstawie wystąpienia na XIV Ogólnopolskim Zjeździe Socjologicznym „Co się dzieje ze społeczeństwem?”, Kraków, 8-11 września 2010, podczas sympozjum „Nowe mechanizmy wytwarzania kultury".

1 Zob. A. Kłoskowska, Socjologia kultury, Warszawa 1983, s. 35.

2 Zob. T. Frank, The Conquest of Cool: Business Culture, Counterculture, and the Rise of Hip Consumerism, Chicago 1997. 
Kultura rozumiana wąsko - jako zespół wytworów symbolicznych poddawanych ocenie estetycznej bądź artystycznej — jest przedmiotem badań, których sens wykracza poza to, czym zajmują się nauki o sztuce i dlatego wymaga analizy socjologicznej oraz antropologicznej. Aktywność określana jako „tworzenie kultury” - wytwarzanie dzieł sztuki czystej, jak sztuki wizualne i literatura, lub użytkowej, jak design i projektowanie graficzne - jest dziedziną, w której w najczystszej postaci realizuje się to, co młody Marks uznawał za istotę człowieka: wytwarzanie przez człowieka jego własnego świata czy też - jeśli chcemy wyrazić to samo w sposób sięgający głębiej do tradycji niemieckiego idealizmu — nadawanie materialnym przedmiotom formy zrodzonej w myśli ${ }^{3}$. Dla Marksa uprzywilejowaną dziedziną aktywności, w której najpełniej wyraża się ta wyjątkowa cecha kondycji ludzkiej, była praca. W Rękopisach ekonomiczno-filozoficznych z 1844 roku pisał:

„[P]rzetwarzanie świata przedmiotowego stanowi dopiero rzeczywiste przyświadczenie człowieka jako istoty gatunkowej. Produkcja ta jest jego czynnym życiem gatunkowym. Dzięki niej przyroda staje się jego dziełem i jego rzeczywistością. Przedmiot pracy jest więc uprzedmiotowieniem życia gatunkowego człowieka: człowiek podwaja się nie tylko intelektualnie, jak w świadomości, lecz czynnie, rzeczywiście, i ogląda siebie w stworzonym przez siebie świecie" 4 .

Inspirującej reinterpretacji diagnoz stawianych przez Marksa i niemiecki idealizm dokonuje Jacques Rancière i to jego tropem idę, wskazując na kulturę jako tę sferę, w której najpełniej wyraża się istota człowieka jako wytwórcy swojego własnego świata. Rancière przywołuje praktykę dwudziestowiecznych awangard, spoglądając na nie przez pryzmat Schillerowskich Listów o estetycznym wychowaniu człowieka. Tradycję awangardową — której ciągła obecność w sztuce współczesnej jest niemożliwa do zanegowania ${ }^{5}$ - Rancière rozumie „nie jako postępowe oderwanie artystycznej nowości od teraźniejszości, ale jako wynajdywanie zmysłowo postrzegalnych form i materialnych ram przyszłego życia" (podkr. - J.S.) ${ }^{6}$. Takie ujęcie, wskazujące właśnie na sztukę jako na domenę, w której twórczość będąca istotą człowieka wyraża się $\mathrm{w}$ formie mniej zniekształconej przez ekonomię polityczną niż w przypadku pracy, pozwala na wyjaśnienie pewnego zjawiska, które może wydawać się

${ }^{3}$ Zob. Najstarszy program systemu niemieckiego idealizmu, w: G. W. F. Hegel, Pisma wczesne z filozofii religii, tłum. G. Sowiński, Kraków 1999. Autorstwo tego tekstu, który zachował się tylko we fragmencie, jest dyskutowane. Często przypisuje się je wspólnie Heglowi, Schellingowi i Hölderlinowi, którzy dzielili pokój w akademiku Seminarium Protestanckiego Tübinger Stift w Tübingen i wtedy — być może - zredagowali swój „manifest”.

4 K. Marks, Rękopisy ekonomiczno-filozoficzne z 1844 r., w: K. Marks, F. Engels, Dzieła zebrane, Warszawa 1962, t. 1, s. 554.

5 Pisałem o tym więcej w tekście Nieznośna uporczywość awangardy, w: Ł. Ronduda (red.), Manifest Nooawangardy. Sztuka $w$ dobie kapitalizmu kognitywnego, posthumanizmu i nauk o złożoności, Warszawa 2009.

${ }^{6}$ J. Rancière, Dzielenie postrzegalnego. Estetyka i polityka, tłum. M. Kropiwnicki, J. Sowa, Kraków 2007, s. 92. 
błahe, dotyka jednak sedna problemu: dzieła sztuki są najdroższymi przedmiotami znajdującymi się w zwyczajnym obiegu handlowym. Oczywiście, niewykrywalne dla radarów myśliwce czy elektrownie atomowe są droższe, jest to jednak inna kategoria towarów. Jeśli chodzi o towary cyrkulujące w obiegu wymiany handlowej, do którego dostęp mają nie tylko rządy czy wielkie firmy, ale zwykli, pojedynczy ludzie, to nic nie przebija cen dzieł sztuki, w tym również sztuki współczesnej. Najdroższa praca żyjącego artysty — rzeźba Damiena Hirsta For the Love of God — została sprzedana w 2007 r. za 100 mln funtów brytyjskich. Teoria estetyczna Rancière’a pozwala doskonale wyjaśnić, skąd bierze się ta wyjątkowa wartość dzieł sztuki, którą trudno wytłumaczyć, odwołując się tylko do kwestii takich jak dystynkcja, a tym bardziej samym zamiłowaniem do rzeczy pięknych. Sztuka jest tak niezwykle ceniona, ponieważ wyraża istotę tego, kim jest człowiek. Czyniąc ze sztuki bajecznie drogi fetysz, człowiek po prostu czci samego siebie. Nie powinno więc być wątpliwości, że kultura jest przedmiotem i polem analizy o najwyższym znaczeniu teoretycznym (oraz społeczno-politycznym). Diagnoza mechanizmów jej wytwarzania pozwala sformułować wiedzę odnoszącą się bezpośrednio do kondycji współczesnego społeczeństwa oraz tworzących je jednostek.

\section{WOBEC HEGEMONA}

Wytwarzanie kultury musi dziś skonfrontować się z tą samą siłą, która kształtuje i reguluje aktywność na wielu innych, jeśli nie na wszystkich, polach życia społecznego - z globalnym, neoliberalnym kapitalizmem. Jest to siła o charakterze hegemoniczym i uniwersalnym. Ilustruje to tematyka rozważań na temat współczesnych mechanizmów wytwarzania kultury. W czasie krakowskiego zjazdu PTS we wrześniu 2010 r. w referatach wygłoszonych w toku sesji poświęconej temu zagadnieniu niemal wszystkie hasła pojawiające się jako główne lub poboczne tematy powiązane były $z$ funkcjonowaniem kapitalizmu: konsumpcja, reklama, przemysł kultury, nowe nośniki muzyki (CD, mp3), przemysł fonograficzny, media, globalizacja, handel muzyką, zacofanie gospodarcze, dostęp do internetu, nowoczesność, płynna nowoczesność, innowacyjność, dobro wspólne i własność intelektualna, prawo autorskie czy wolne oprogramowanie. Zwłaszcza ta ostatnia kwestia odnosi się bezpośrednio do funkcjonowania współczesnego kapitalizmu. Jej istotą nie jest dylemat, czy można czy nie można skopiować film lub piosenkę, ale jaki będzie model własności środków produkcji; bo nikt nie wątpi, że w epoce kapitalizmu kognitywnego oprogramowanie komputerowe jest jednym $z$ najistotniejszych środków produkcji. Z punktu widzenia kwestii, którymi zajmowali się marksiści, począwszy od Karola Marksa aż po Antonia Negriego i innych włoskich postoperaistów, jest niesłychanie interesujące, że sedno argumentacji zwolenników wolnych i otwartych licencji dotyczy problemu prywatyzowania owoców produkcji intelektualnej, rozumianego jako odebranie 
komuś dostępu do nich, wyłączenie jego lub jej z tego, co wspólne (ang. the common).

Jest zaskakujące, jak rzadko w tego rodzaju debatach i rozważaniach pojawia się termin „kapitalizm”. Sytuacja jest ciekawa z dekonstrukcyjnego punktu widzenia, ponieważ mamy oto nieobecny element będący podstawą dyskursywnej ramy, w której się poruszamy. Gdybyśmy mieli ten dekonstrukcyjny wątek

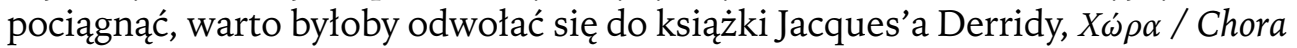
poświęconej platońskiej koncepcji czegoś, co stanowi uniwersalną, chociaż bezpośrednio niedostępną podstawę istnienia przestrzeni i przestrzennych relacji ${ }^{7}$. Kapitalizm to dzisiaj właśnie $X \hat{\omega} \rho \alpha$ — powszechna zasada organizacji wielu pół społecznych, w tym również kultury, wyłączana jednak poza dyskursywną ramę każdego z tych pól. W dobitny sposób uwidocznił to Kongres Kultury Polskiej w 2009 r., na którego otwarciu przemawiał Leszek Balcerowicz, a Ministerstwo Kultury i Dziedzictwa Narodowego zaprezentowało program reformy kultury skonstruowany w duchu tzw. porozumienia waszyngtońskiego ${ }^{8}$ przez ekonomistę Jerzego Hausnera ${ }^{9}$.

\section{NIEZALEŻNOŚĆ - W POSZUKIWANIU NIEWYALIENOWANYCH FORM WYTWARZANIA KULTURY}

Szczegółowy problem, którym chciałbym się tu zająć, dotyczy formy. Interesują mnie poszukiwania form, które pozwoliłyby na dezalienację kultury jej wytwarzania, instytucji, w ramach których się ono dokonuje, ostatecznego efektu owego procesu wytwarzania oraz dezalienację kultury jako sfery życia, z której spora część społeczeństwa obecnie pozostaje wyłączona. Innym, bardziej popularnym terminem, którym można określić tę samą kwestię byłoby „uczestnictwo”. Hasło to pojawia się często przy okazji dyskusji na temat kultury, jej dostępności czy sposobów jej produkcji. „Uczestnictwo” i „dezalienacja" to terminy, których można używać niemalże zamiennie, trzeba mieć jednak świadomość, że pochodzą one $z$ innych tradycji intelektualnych czy porządków teoretycznych. Odwołując się do podziału na teorię tradycyjną i teorię krytyczną, dokonanego przez Maxa Horkheimera ${ }^{10}$, proponuję umieścić uczestnictwo w ramach pierwszej, a dezalienację — drugiej. Niezależnie od tego, za

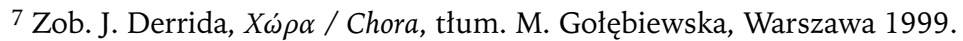

8 Więcej na ten temat zob. np. L. C. Bresser Pereira, J. M. Maravall, A. Przeworski, Economic Reforms in New Democracies: A Social-Democratic Approach, Cambridge 1993.

9 Pisałem o tym więcej w tekście Rewolucja kulturalna — tak, ale jaka? O możliwych kierunkach polskiej polityki kulturalnej („Zarządzanie Kulturą” 2010, nr 3). Pełną treść tzw. raportu Hausnera zob. M. Buczek i in., Kultura w kryzysie czy kryzys w kulturze. Raport przygotowany na zlecenie Ministerstwa Kultury i Dziedzictwa Narodowego, http://www.kongreskultury.pl/library/File/Hausner/Kultura\%20w \%20kryzysie\%20czy\%20kryzys\%20w\%20kulturze_wpelna.pdf.

10 Zob. M. Horkheimer, Teoria tradycyjna a teoria krytyczna, tłum. J. Łoziński, w: J. Łoziński (red.), Szkoła frankfurcka, Warszawa 1987, t. 2, s. 137-171. 
którą opcją się opowiadamy — mój wybór, podobnie jak wybór wielu badaczy kultury od Waltera Benjamina po Stuarta Halla i Waltera Bena Michaelsa, pada na teorię krytyczną - wymiar uczestnictwa/dezalienacji musimy uznać za podstawowy wymiar istnienia kultury w ogóle. Parafrazując fenomenologiczną tezę o tetycznym charakterze świadomości, którą wyraża znana maksyma Husserla, że świadomość jest zawsze świadomością czegoś, można powiedzieć, że kultura jest zawsze kulturą czyjąś — tych, którzy ją wytarzają i tych, którzy dzięki uczestnictwu potrafią rozpoznać w niej siebie samych. W innej sytuacji kultura przestaje być kulturą, a staje się instrumentem (jak w przypadku zawłaszczenia sztuki przez marketing i public relation) lub usługą i towarem (zawłaszczenie przez przemysły kultury).

Kwestia formy, która organizuje proces wytwarzania kultury, ma pewien uniwersalny aspekt wykraczający poza pole kultury jako takiej. Kwestie uczestnictwa i dezalienacji pojawiają się współcześnie w dyskusjach dotyczących innych pól aktywności społecznej: w urbanistyce i architekturze (narracja „prawa do miasta" od Lefebvre'a po Harveya ${ }^{11}$ ), teorii politycznej (demokracja uczestnicząca, o której w Polsce wiele pisał Rafał Górski ${ }^{12}$ ), teorii kapitału społecznego (Bourdieu, Coleman, Putnam) czy w debatach na temat praw migrantów i mniejszości kulturowych ${ }^{13}$. Z tego powodu pytanie o formy wytwarzania kultury, jakie chciałbym tu zadać, stawiam w perspektywie strukturalistycznej, zgodnie z tym jak strukturalizm ujmował Gilles Deleuze: relacja między miejscami w strukturze jest ważniejsza od tego, co te miejsca zajmuje ${ }^{14}$. Wypowiadam się więc zdecydowanie przeciw perspektywie poststrukturalistycznej (a szerzej postmodernistycznej), która odwraca tę hierarchię ważności ${ }^{15}$.

\section{ILUZJE NIEZALEŻNOŚCI, CZYLI O ŚMIERCI TRZECIEGO SEKTORA}

Perspektywa teoretyczna i dokonane przeze mnie wybory konceptualne są już wystarczająco dobrze zarysowane, abyśmy mogli przejść do właściwego tematu, czyli tego, w jaki sposób w najnowszej kulturze — zarówno polskiej, jak i światowej - realizuje się dążenie do uczestnictwa i dezalienacji i jak kształtowało ono mechanizmy wytwarzania kultury przez ostatnie dwie dekady. Proponuję przyjąć taki właśnie horyzont czasowy analizy, który — moim zdaniem

11 Zob. H. Lefebvre, Le droit à la ville, Paris 1968; D. Harvey, Prawo do miasta, tłum. E. Majewska, w: J. Sokołowska (red.), Robotnicy opuszczają miejsca pracy, Łódź 2010.

12 Zob. R. Górski, Bez państwa. Demokracja uczestnicząca w działaniu, Kraków 2007.

13 Zob. G. Agamben, Homo sacer. Suwerenna wtadza i nagie życie, tłum. M. Salwa, Warszawa 2008; A. Gawkowska, Biorac wspólnotę poważnie? Komunitarystyczne krytyki liberalizmu, Warszawa 2004.

14 G. Deleuze, Po czym rozpoznać strukturalizm?, tłum. S. Cichowicz, w: M. J. Siemek (red.), Drogi wspótczesnej filozofii, Warszawa 1978, s. 293.

15 F. Jameson, Postmodernism, or, The Cultural Logic of Late Capitalism, London 1991; S. A. Tyler, Przed-się-wzięcie post-modernistyczne, tłum. O. i W. Kubińscy, w: M. Buchowski, Amerykańska antropologia postmodernistyczna, Warszawa 1999. 
— możemy utożsamić ze współczesnością. Ma to sens zwłaszcza w kontekście polskim, gdzie przełom lat osiemdziesiątych i dziewięćdziesiątych XX wieku w wielu wymiarach życia społecznego miał postać radykalnego cięcia.

Konsekwencje tego cięcia objawiły się również w kulturze, przyjmując formę podobną do przeobrażeń $w$ innych dziedzinach rzeczywistości społecznej. Były to zmiany typowe dla wejścia $\mathrm{w}$ porządek liberalno-nowoczesny i polegały na intensywnym ożywieniu aktywności obywatelskiej. W sferze gospodarczej rozwój społeczeństwa obywatelskiego ${ }^{16}$ objawił się przejściem od państwowej do prywatnej własności środków produkcji, w kulturze natomiast jego manifestacją był rozkwit trzeciego sektora, czyli obywatelskich organizacji pozarządowych (stowarzyszenia i fundacje). Pojawiły się również prywatne instytucje kultury, jest ich jednak stosunkowo niewiele i nie odgrywają wielkiej roli na polskiej scenie artystycznej, gdzie - co symptomatyczne dla przemian trzeciego sektora w ostatnich dekadach - nawet podmioty prowadzące aktywną działalność komercyjną (np. Art Stations Foundation 5050 Grażyny Kulczyk, Fundacja Galerii Foksal czy galeria Raster) mają instytucjonalną formę organizacji obywatelskiej (odpowiednio fundacja w przypadku Grażyny Kulczyk oraz FGF i stowarzyszenie w przypadku Rastra).

Gwałtowny rozwój instytucji trzeciego sektora w Polsce po roku 1989 jest faktem powszechnie znanym i świetnie opisanym. Monitoring ich aktywności na bieżąco prowadzi Stowarzyszenie Klon/Jawor, które regularnie publikuje na ten temat raporty ${ }^{17}$. Szkoda więc miejsca na ich streszczanie czy omawianie. Przytoczę tylko jeden fakt: w latach 2006-2009 w Polsce powstało 10 tys. nowych fundacji i 2 tys. stowarzyszen ${ }^{18}$, co oznacza, że przez te trzy lata powstawało codziennie ponad dziesięć nowych organizacji pozarządowych. W 2008 r. 12,7\% z nich deklarowało, że ich głównym polem działalności jest kultura ${ }^{19}$, co oznacza, że między rokiem 2006 a 2009 każdego dnia mieliśmy w Polsce o jedną organizację pozarządową zajmującą się kulturą więcej. I rzeczywiście, wpływ i znaczenie tego typu instytucji są niemożliwe do zanegowania: Fundacja Wyspa Progress, Stowarzyszenie Integracji Kultury, Fundacja Korporacja Ha!art, Fundacja Galerii Foksal, Stowarzyszenie im. Stani-

16 Termin ten rozumiem tak jak Antonio Gramsci, czyli jako obszar aktywności obywateli niezależny od funkcjonowania społeczeństwa politycznego (władzy państwowej). Zob. np. S. Jones, Antonio Gramsci, London 2006, s. 32-33. Rozróżnienie to, które ma źródło w filozofii Hegla, jest dzisiaj powszechnie przyjętym sposobem definiowania społeczeństwa obywatelskiego również w obrębie teorii tradycyjnej.

17 Zob. np. Podstawowe fakty o organizacjach pozarzadowych. Raport $z$ badania 2008, Warszawa 2009, http://civicpedia.ngo.pl/files/civicpedia.pl/public/kondycja2008.pdf. Zob. również stronę „Civicpedia. Badania społeczeństwa obywatelskiego”, http://civicpedia.ngo.pl/.

18 Zob. Rodzaje i liczba organizacji. Podstawowe dane, Civicpedia, http://civicpedia.ngo.pl/x/328111 \#badania_2008; M. Gumkowska, J. Herbst, Podstawowe fakty o organizacjach pozarzadowych. Raport $z$ badania 2006, Warszawa 2006, s. 5.

19 Zob. Podstawowe fakty o organizacjach pozarzadowych, cyt. wyd., s. 5. 
sława Brzozowskiego czy Fundacja Nowej Kultury Bęc Zmiana - aby wymienić tylko niektóre - to organizacje, bez których kultura polska wyglądałaby inaczej.

Teoria socjologiczna każe nam jednak spodziewać się jeszcze większych korzyści płynących $z$ pojawienia się tych nowych $w$ Polsce form wytwarzania kultury. Znamy doskonale apologie aktywności obywatelskiej formułowane w myśli społecznej od Alexisa de Tocqueville'a ${ }^{20}$ po Roberta Putnama ${ }^{21}$ przez Edwarda Banfielda ${ }^{22}$, Jamesa Colemana ${ }^{23}$, Jane Jacobs ${ }^{24}$ i Pierre'a Bourdieu ${ }^{25}$. Jak przekonują oni wszyscy, trzeci sektor ma funkcję inkubatora kapitału społecznego, który walnie przyczynia się do realizacji różnego rodzaju działań, nie tylkow tym obszarze aktywności społecznej, gdzie został wygenerowany. Nie przypadkiem zresztą hasło „społeczeństwo obywatelskie" było jednym z terminów-wytrychów transformacji. Miała ona stworzyć społeczeństwo obywatelskie, dać obywatelom możliwość swobodnego działania i $\mathrm{w}$ ten sposób doprowadzić do zmiany społecznej. Dlatego też z pojawienia się nowych, bardziej obywatelskich form wytwarzania kultury korzyści powinno odnosić całe społeczeństwo.

Tu jednak zaczynają się schody. Wnioski, jakie płyną z badań nad kapitałem społecznym, są doskonale i wielokrotnie potwierdzone. Trudno byłoby je podważyć. Trzeci sektor jest jednak dzisiaj bardziej nazwą problemu niż rozwiązania, co wynika ze zmiany sposobu funkcjonowania organizacji pozarządowych. To, z czym mamy obecnie do czynienia, to nie realizacja obietnicy trzeciego sektora, ale raczej ruiny jego utopii. Sytuację tę świetnie przedstawiła w $2005 \mathrm{r}$. Agnieszka Rymsza, relacjonując badania i dyskusje dotyczące zmian w trzecim sektorze od kilku dekad prowadzone w Stanach Zjednoczonych ${ }^{26}$. Autorka pokazuje, że od lat sześćdziesiątych postępuje tam wzrost zainteresowania państwa i administracji państwowej trzecim sektorem. Zgodnie $z$ koncepcją third party government Lestera Salamona, rząd określa priorytetowe zadania do realizacji, daje na nie pieniądze, a trzeci sektor realizuje te przedsięwzięcia. Ma to być sposób na odciążenie administracji państwowej i stworzenie obywatelom możliwości swobodnego działania.

20 Zob. A. de Tocqueville, O demokracji w Ameryce, tłum. B. Janicka, M. Król, t. 1, Kraków 2003.

21 Zob. R. D. Putnam, Demokracja $w$ dziataniu. Tradycje obywatelskie we wspótczesnych Wtoszech, tlum. J. Szacki, Kraków 1995.

22 Zob. E. C. Banfield, The Moral Basis of a Backward Society, New York 1958.

23 Zob. J. S. Coleman, Social Capital in the Creation of Human Capital, „The American Journal of Sociology" 1988, t. 94, supplement: Organizations and Institutions: Sociological and Economic Approaches to the Analysis of Social Structure.

24 Zob. J. Jacobs, The Death and Life of Great American Cities, New York 1961.

25 Zob. P. Bourdieu, The Forms of Capital, w: J. G. Richardson (red.), Handbook of Theory and Research for the Sociology of Education, New York 1986.

26 Zob. A. Rymsza, Partnerzy stużby publicznej? Wyzwania wspótpracy sektora pozarządowego z administracja publiczna w świetle doświadczeń amerykańskich, „Trzeci Sektor” 2005, nr 3. 
Przywoływana wyżej teoria kapitału społecznego dostarcza obszernej podbudowy teoretycznej dla tego rodzaju polityki. Rymsza, powołując się na książkę Stevena Smitha i Michaela Lipsky'ego Nonprofits for Hire: The Welfare State in the Age of Contracting, pokazuje jednak, że proces przerzucania zadań administracji publicznej na trzeci sektor, ma bardzo negatywne konsekwencje dla funkcjonowania organizacji pozarządowych. Działalność NGO jest traktowana tylko jako pewien sposób kompensowania niesprawności państwa. Pieniądze przekazuje się trzeciemu sektorowi pod warunkiem akceptacji standardów działania, które są typowe dla administracji publicznej, nie pasują jednak do sposobu funkcjonowania społeczeństwa obywatelskiego. Duży nacisk kładziony jest na profesjonalizację, nadzór, standaryzację itp., gdy tymczasem organizacje obywatelskie zawsze opierały się na entuzjazmie, dobrej woli, poświęceniu i zaufaniu. Propagowanie standardów społeczeństwa politycznego wśród organizacji obywatelskich i urządowienie (ang. governamentalization) trzeciego sektora nie tylko prowadzi do degeneracji etosu obywatelskiego, ale również osłabia prospołeczną funkcję, którą pełnił trzeci sektor. Traci on swoją misję i przestaje być inkubatorem kapitału społecznego. Stowarzyszenia i fundacje $\mathrm{z}$ organizacji pozarządowych stają się pararządowymi. Zmianę tę $\mathrm{w}$ żartobliwy sposób opisuje termin GONGO — Government Organized Non-Governmental Organization ${ }^{27}$.

To przerzucanie funkcji administracji państwowej na trzeci sektor jest procedurą władzy o wybitnie neoliberalnym charakterze. Organizacje trzeciego sektora są zmuszone do działania w sposób jak najbardziej rynkowy. Startując w konkursach grantowych, muszą zaproponować jak najniższe koszty realizacji danego zadania, co w praktyce prowadzi do wyzysku darmowej siły roboczej, jaką jest $\mathrm{w}$ trzecim sektorze wolontariat. A trzeba pamiętać, że idea dobrowolnej aktywności obywatelskiej, którą w Ameryce podziwiał de Tocquevlille, a w północnych Włoszech Putnam, miała zupełnie inny sens i cel. Co więcej, ponieważ projekty NGO-sów realizowane są w horyzoncie czasowym jednego roku (dotacje wieloletnie są rzadkościa), gdy jakaś organizacja lub projekt stają się niewygodne lub przestają być dla rządu priorytetowe, po prostu odcina się im finansowanie i nikomu z niczego nie trzeba się tłumaczyć. Prowadzenie przez urzędników de facto arbitralnej polityki jest w tej sytuacji o wiele prostsze niż wtedy, gdy te same projekty realizowane są przez sektor publiczny, w którym trzeba ogłaszać wieloletnie strategie, zatrudniać ludzi, których później nie można od ręki zwolnić itp. Trzeci sektor jest $z$ tego punktu widzenia bardzo wygodny. Pozwala, mówiąc po Baumanowsku, dowolnie wałkować i przemielać siły wytwórcze społeczeństwa i używać ich do doraźnych celów definiowanych przez polityków oraz biurokratów.

27 Termin ten poznałem dzięki referatowi Tomasza Szkudlarka „Społeczeństwo wiedzy i jego robotnicy”, który został wygłoszony 7 grudnia 2009 r. w Warszawie podczas Drugiego Zjazdu Wolnego Uniwersytetu Warszawy nt. „Przemysły kreatywne i fabryki wiedzy. Analiza i opór”. 
Zarządzanie kulturą coraz powszechniej jest realizowane przez takie właśnie regulowanie aktywności trzeciego sektora. W praktyce realizuje się to przez określanie najróżniejszego rodzaju tematów, organizowanie sezonów kulturalnych, wyznaczanie priorytetów itp. W roku 2009, aby uzyskać finansowanie, trzeba było wymyśleć projekt kulturalny związany z Chopinem, w roku 2010 na topie była prezydencja Polski w Unii Europejskiej i sposobem na finansowanie kultury tzw. niezależnej było wskazanie powiązania z promocją tej prezydencji. Co bardzo ważne, zarówno w kulturze, jak i na innych polach organizacje trzeciego sektora realizujące owe priorytetowe tematy nie mają nic do powiedzenia, jeśli chodzi o ich ustalanie. Są one formułowane odgórnie, a następnie przedstawiane jako jedyne możliwe zadania do realizacji dla organizacji starających się o dotacje. Niewiele ma to wspólnego z uczestnictwem w kulturze i autentyczną, dezalienującą aktywnością obywatelską, dzięki której można „Wziąc sprawy w swoje ręce”. Powstaje raczej relacja kliencka polegająca na dostarczaniu usług, za które patron jest skłonny zapłacić. Oznacza to kres złudzeń, że instytucje trzeciego sektora pozwalają osiągnąć niezależność w wytwarzaniu kultury i dzięki temu zrealizować jakiekolwiek idee uczestnictwa, o dezalienacji w ogóle nie wspominając. Pole tzw. aktywności obywatelskiej okazuje się tak samo wyalienowane jak żywiołowa przestrzeń gospodarki i rynku.

Obecnie choroba uzależnienia aktywności społeczeństwa obywatelskiego od władzy politycznej wchodzi w nowy etap. Z fazy biernej — czyli sterowania trzecim sektorem przez manipulowanie priorytetami programów grantowych - władza przeszła do fazy czynnej: systemem zachęt i podniet stymuluje powstawanie $\mathrm{w}$ trzecim sektorze projektów oraz organizacji służących realizacji określonych wcześniej przez władze celów. Kultura jest, niestety, szczególnie podatna na tego rodzaju korupcję. Mnożą się więc fundacje, które po kilku miesiącach - lub nawet tygodniach — istnienia startują do konkursów o wielosettysięczne lub wielomilionowe dotacje i... wygrywają je. Czasem wygląda to nawet tak, jakby urzędnicy celowo wyszukiwali organizacje słabe, o mizernym dorobku, kiepsko zdefiniowanej tożsamości i rozmytych celach: „prowadzenie analiz i studiów z zakresu sztuki współczesnej, aktualnej; gromadzenie prac i dzieł z zakresu sztuk wizualnych w celu udostępniania ich społeczeństwu; współpraca z krajowymi i zagranicznymi instytucjami kulturalnymi działającymi w zakresie objętym celem Fundacji oraz osobami wykazującymi zainteresowanie celem Fundacji; dokumentowanie zbiorów Fundacji i wydarzeń metodą elektroniczną, drukiem itp.; organizację spotkań i sympozjów z zakresu sztuki współczesnej" ${ }^{28}$. Instytucje takie doskonale nadają się do realizowania łatwych, lekkich i przyjemnych przedsięwzięć oraz osiągania celów, którym zdaniem biurokratów - powinna służyć kultura: kreowanie pozytywnego wizerunku miasta, ściąganie inwestorów, dekorowanie przestrzeni miejskiej miał-

28 Strona WWW Fundacji Wschód Sztuki, http://www.fws.art.pl/. 
kimi instalacjami zwanymi potem szumnie „sztuką w przestrzeni publicznej”, stymulowanie turystyki itp. Przykład? Krakowska Fundacja Wschód Sztuki i jej festiwal ArtBoom - półtora miliona złotych przepompowane przez „organizację pozarządową" będącą de facto przystawką do komercyjnej, trzecioligowej galerii i przeznaczone na wydarzenie, którego sens jest przede wszystkim marketingowy: zwabić do Krakowa turystów, ale nie na tanie piwo, tylko na sztukę. Nic dziwnego, że lwia część budżetu tego przedsięwzięcia poszła na kampanię reklamową ${ }^{29}$.

Jest symptomatyczne, że pomysł reformy kultury, który w 2009 r. zaproponowało Ministerstwo Kultury i Dziedzictwa Narodowego, polega w dużej mierze na przerzuceniu wytwarzania kultury na organizacje trzeciego sektora. Pomysł ten próbowano sprzedać pod szyldem retoryki proobywatelskiej i stymulowania oddolnej aktywności społeczeństwa. Oczywiście, jak można się domyślić, znając neoliberalne dogmaty porozumienia waszyngtońskiego, ma się to dokonać kosztem redukcji sektora publicznego. Nie jest więc zaskakujące, że w czasie inauguracji Kongresu Leszek Balcerowicz nazwał polskie publiczne instytucje kultury bastionem homo sovieticus i w telewizyjnych wywiadach przekonywał później, że popiera reformę Hausnera, ponieważ wierzy ludziom, a nie państwu. Widzimy więc znów, jak pod pretekstem uczestnictwa przemyca się nowe formy kontroli.

\section{W POSZUKIWANIU ROZWIĄZANIA ALTERNATYWNEGO}

Jak wybrnąć z tego klinczu? Czy mogą istnieć niewyalienowane, partycypacyjne formy wytwarzania kultury? Nie chcę uprawiać defetyzmu i wpisywać się w popularne w Polsce narzekanie ${ }^{30}$. Zwłaszcza że rozwiązania, które można by wprowadzić w życie, są nie tylko opisane teoretycznie (a przynajmniej część $z$ nich), ale również przetestowane w praktyce. Przedstawię je tu skrótowo i hasłowo.

Najprostszą i najbardziej oczywistą zmianą byłaby próba odbudowy etosu trzeciego sektora. Wymagałoby to reform $w$ dwóch sferach. Po pierwsze, $w$ polityce wobec samych NGO-sów. O dwóch bardzo prostych i możliwych do wprowadzenia w każdej chwili zmianach od dłuższego czasu mówi środowisko organizacji pozarządowych: finansowanie w horyzoncie czasowym dłuższym niż jeden rok (optymalne byłyby programy trzyletnie) oraz wprowadzenie grantów strukturalnych, przeznaczonych na samo utrzymanie się stowarzyszeń i funda-

29 Obszerniejszą analizę problemu urządowienia i komercjalizacji trzeciego sektora zob. J. Sowa, Goldex Poldex Madafaka, czyli raport z (oblężonego) Pi sektora, w: Europejskie polityki kulturalne 2015, Warszawa 2009.

30 Chociaż podobno na najstarszych babilońskich tablicach odnaleziono utyskiwania, że młodzież jest zepsuta, a państwo w stanie upadku, być może więc narzekanie i defetyzm są uniwersalnymi przypadłościami natury ludzkiej, a nie cechą polskiego habitusu narodowego. 
cji, a nie tylko na konkretne programy. Zmniejszyłoby to wyzysk wolontariatu oraz ograniczyło doraźny charakter realizowanych projektów. Druga bardzo ważna zmiana to dopuszczenie organizacji trzeciego sektora do podejmowania decyzji o priorytetach i tematach konkursów grantowych. Bez tego konkursy są tylko zakamuflowanym sposobem zarządzania trzecim sektorem i źródłem uzależnienia społeczeństwa obywatelskiego od społeczeństwa politycznego. Taki stan rzeczy to patologia nawet z punktu widzenia ideologii czysto liberalnej, nie mówiąc o jakichkolwiek ideałach emancypacyjnych.

Druga sprawa: rozwój trzeciego sektora nie powinien dokonywać się kosztem osłabiania instytucji publicznych. Jeśli organizacje pozarządowe mają generować jakąś wartość dodatkową dla całego społeczeństwa, jak opisuje to teoria kapitału społecznego, nie mogą być traktowane jako sposób na kompensację słabości sektora publicznego. Przeprowadzone we Włoszech badania Roberta Putnama pokazują, że zależność między sektorem publicznym a sektorem obywatelskim jest odwrotna: to dzięki akumulacji kapitału w organizacjach obywatelskich możliwe jest sprawne działanie instytucji publicznych. Oczywiście, sytuacja sektora publicznego w Polsce jest tematem na osobny artykuł, jeśli nie książkę. Jego słaba kondycja wynika nie tylko z niedostatków materialnych, ale również $z$ fatalnych procedur, według których funkcjonuje. Najlepszy tego przykład to brak konkursów na stanowiska kierownicze w wielu instytucjach kultury i ich obsadzanie na drodze mianowania. Przypomina to bardziej feudalną inwestyturę niż zasady działania nowoczesnego społeczeństwa.

Dyskutując o możliwych reformach trzeciego sektora, trzeba pamiętać o jednym ograniczeniu, które sprawia, że ich rezultaty mogą być gorsze niż w pierwszej chwili mogłoby się wydawać. Organizacje obywatelskie nie działają w próżni, ale w środowisku społecznym, które o wiele silniej od nich i przynajmniej równie silnie co państwo kształtuje inna potężna siła: kapitał. Ekspansja kapitalizmu ma charakter nie tylko geograficzny. Zachodzi również wewnątrz tkanki społecznej, promując określony rodzaj rządomyślności, aby posłużyć się pojęciem stworzonym przez Michela Foucaulta. Komercjalizacja $\mathrm{i}$ instrumentalizacja trzeciego sektora to tylko jeden $z$ przykładów formatowania życia społecznego zgodnie z zasadami dyktowanymi przez kapitał (urynkowienie, prywatyzacja, konkurencyjność, nastawienie na mierzalny efekt, zarządzanie zgodnie $z$ biznesowymi zasadami itp.). Kultura jest w Polsce i tak jednym $z$ ostatnich pól poddawanych podobnemu dyscyplinowaniu. Proces ten rozpoczął się $\mathrm{w}$ późnych latach osiemdziesiątych w gospodarce, a w ostatniej dekadzie objął swoim zasięgiem służbę zdrowia (komercjalizacja szpitali), kulturę (program Hausnera) oraz szkolnictwo wyższe i naukę (reformy Kudryckiej). Aby skutecznie przeciwdziałać tym zmianom, musielibyśmy najpierw rozpoznać wspólną naturę, przyczynę i cel przekształceń zachodzących w tych pozornie niezależnych od siebie sektorach społeczeństwa (czyli hegemoniczną pozycję kapitału w przestrzeni społecznej). Możliwości ich korygowania są niewielkie, jeśli ograniczymy się do tylko jednego sektora, na przykład kultury. 
Jednocześnie warto rozważyć kwestie poszukiwania nowych, bardziej demokratycznych i partycypacyjnych mechanizmów wytwarzania kultury i form zarządzania jej instytucjami. Wracamy tu do sygnalizowanego na początku pytania o uczestniczące, niewyalienowane formy i struktury mające zastosowanie szersze niż tylko funkcjonowanie kultury. Zmianę w tym kierunku możemy zdefiniować jako dalszą demokratyzację życia społecznego, zgodną z ideałami, które powszechnie przyjmujemy jako zasady regulujące nasze życie społeczne i polityczne: upodmiotowienie, oddanie decyzji tym, których one dotyczą, demokratyczna kontrola nad procesem decyzyjnym itp. Forma, jaką można by tu zastosować, już istnieje. Opisuje ją obszernie Rafał Górski w książce Bez państwa. Demokracja uczestniczaca $w$ działaniu ${ }^{31}$. Jej istotą jest eliminacja reprezentacji politycznej na korzyść bezpośredniego podejmowania decyzji, czyli „samoregulacja mnogości poprzez decyzję większości”, aby użyć sformułowania Jacquesa Rancière'a ${ }^{32}$. Procedury oparte na tej zasadzie wcielano w życie w skali całych miast, liczących nawet ponad milion mieszkańców. Najbardziej znanym przykładem jest tzw. budżet partycypacyjny w brazylijskim Porto Allegre.

Postulat zastosowania tego rodzaju mechanizmów pojawił się w 2009 r. w Manifeście Komitetu na Rzecz Radykalnych Zmian w Kulturze ${ }^{33}$. Pierwsza z czterech propozycji Komitetu zakłada „likwidację centralnego, biurokratycznego modelu zarządzania kulturą i utworzenie społecznych rad do spraw kultury i sztuki". Autorzy manifestu tak przedstawiają w zarysie swoją propozycję:

„Rady (regionalne i/lub ogólnokrajowa) miałyby władzę nad wszystkimi instytucjami zajmującymi się tworzeniem oraz rozpowszechnianiem kultury (w tym nad szkołami artystycznymi); w radach obecni byliby przedstawiciele zarówno twórców, jak i odbiorców kultury (wybierani zgodnie z zasadami demokracji uczestniczącej, podobnie np. do sposobu działania tzw. budżetów partycypacyjnych), system wyłaniania rad miałby jednak charakter mieszany (politeo-demokratyczny czy też merytokratyczno-demokratyczny), tak aby twórcy kultury mieli większy wpływ na działanie rad niż wynikać by to mogło $z$ ich zwykłej liczby. Dzięki radom kultura stałaby się faktycznie publiczna, a nie państwowa. Nie byłaby zabawką w rękach biurokratów i polityków, którzy wykorzystują ją do swoich partykularnych, prywatnych interesów (promocja, propaganda polityczna, agitacja wyborcza itd.). Urzędy administracji centralnej czy samorządowej miałyby jedynie funkcje wykonawcze, konsulatcyjne i administracyjne. To rady byłyby ośrodkami demokratycznej władzy funkcjonującej w oparciu o czynniki merytoryczne, a nie interes poszczególnych grup politycznych. Rady miałyby realne prerogatywy i kompetencje w zakresie podejmowania decyzji i kontroli

31 Zob. R. Górski, Bez państwa, cyt. wyd.

32 J. Rancière, Koniec polityki, czyli realistyczna utopia, tłum. I. Bojadżijewa, J. Sowa w: J. Rancière, Na brzegach politycznego, Kraków 2008, s. 49.

33 Stworzyli go ważni polscy artyści, między innymi Zbigniew Libera, Roman Dziadkiewicz i Janek Simon, kuratorzy i animatorzy kultury, jak Bogna Świątkowska, Jakub Szreder czy Joanna Warsza oraz teoretycy, między innymi Ewa Majewska i Grzegorz Jankowicz. 
działań urzędników, czym różniłyby się od obecnych ciał opiniujących i doradczych, które często są jedynie listkami figowymi biurokratycznej kontroli” ${ }^{34}$.

Co ciekawe, podobny system został już w małej skali zastosowany i przetestowany na polu kultury. W 2004 r. w Wiedniu powstała platforma zwana NetzNetz, która służy demokratycznemu podziałowi środków wyasygnowanych przez miasto na sponsorowanie sztuki sieci (netart) ${ }^{35}$. Tworzy ją kilkaset osób i organizacji zainteresowanych działaniem w tej dziedzinie. Miasto, zamiast rozdawać pieniądze poprzez konkursy grantowe, oddaje im do dyspozycji całą kwotę, którą sami dystrybuują na zasadach ustalonych w toku dyskusji i głosowania (zgłaszanie propozycji i ich zbiorowe głosowanie zgodnie $z$ ordynacją preferencyjna). Jest to sposób na rzeczywiste, a nie tylko formalne, upodmiotowienie społeczeństwa obywatelskiego i jego uniezależnienie od społeczeństwa politycznego.

Wreszcie trzeci pomysł na nowy, niewyalienowany mechanizm wytwarzania kultury. Byłoby to coś różnego od istniejących form pierwszego, drugiego i trzeciego sektora. W tekście napisanym dwa lata temu na zamówienie Wolnego Uniwersytetu Warszawy i Fundacji Bęc Zmiana zaproponowałem termin na określenie tej nowej formy: Pi sektor ${ }^{36}$. O co chodzi w tym pojęciu? Trzeciemu sektorowi można przeciwstawić zupełnie niesformalizowany obszar wytwarzania kultury - czwarty sektor. Są to squaty, niesformalizowane, amatorskie grupy twórcze, samizdaty, prywatne galerie w mieszkaniach, spontaniczne, streetartowe interwencje w przestrzeń miasta itp. Sektor ten jest ostentacyjnie antyestablishmentowy, zarówno w odniesieniu do władzy (miejskie wydziały kultury, państwowe instytuty, ministerstwo), jak i kapitału (media, rynek sztuki itp.). Nie tylko nie wchodzi we współpracę z organizacjami państwowymi i prywatnymi, ale jest w ogóle przeciw całej tej sferze, pozostając poza nią. Wydaje mi się, że między trzecim a czwartym sektorem można skonstruować model działania, który nazwałem Pi sektorem, ponieważ jest ułamkowym sektorem wytwarzania kultury, wbijającym się między logikę trzeciego i czwartego sektora. Instytucją Pi sektora jest na przykład krakowska Spółdzielnia Goldex Poldex ${ }^{37}$ — organizacja w żaden sposób niesformalizowana prawnie i oparta na modelu funkcjonowania spółdzielni w sensie źródłowym, czyli „wspólnego dzielenia” kosztów i działania w grupie, które daje synergiczną możliwość zrealizowania projektów niemożliwych do przeprowadzenia $\mathrm{w}$ pojedynkę. W Polsce pionierem tego rodzaju działania była w latach osiemdziesiątych XX wieku łódzka Kultura Zrzuty.

\footnotetext{
${ }^{34}$ R. Dziadkiewicz, G. Jankowicz, Z. Libera, E. Majewska, L. Makowska, N. Romik, J. Simon, J. Sowa, K. Szreder, B. Świątkowska, J. Warsza, Manifest Komitetu na Rzecz Radykalnych Zmian w Kulturze. Manifest, ogłoszony w internecie, był przedrukowany w piśmie „FORMAT P” 2010, nr 3.

35 Zob. „NetzNezt Wiki”, http://netznetz.net/wiki/Hauptseite.

36 J. Sowa, Goldex Poldex Madafaka, czyli raport z (oblężonego) Pi sektora, cyt. wyd.

37 Zob. http://goldexpoldex.pl/.
} 
Od trzeciego sektora taki model odróżnia się stosunkiem do establishmentu: unika uzależnienia od publicznego finansowania, eksponowania logotypów sponsorów, pisania sprawozdań, osiągania założonych wskaźników itp. Od czwartego sektora natomiast Pi sektor różni się tym, że nie stara się stworzyć osobnego obiegu, znaleźć się na zewnątrz świata, w którym działa państwo i kapitał. Jego funkcjonowanie opiera się na założeniu, że istnieje tylko jeden świat pozbawiony zewnętrza ${ }^{38}$. Nie chodzi więc o stworzenie w nim innej, całkowicie niezależnej przestrzeni wytwarzania kultury, ale o to, by na własnych zasadach i dzięki własnym zasobom uczestniczyć w tworzeniu i kształtowaniu jednej, wspólnej przestrzeni.

Skuteczność strategii Pi sektora w wytwarzaniu kultury jest trudna do zanegowania. Przykład dotychczasowej działalności Goldexu pokazuje, jakie są jego szanse i ograniczenia: organizacja de facto hobbystyczna, prowadzona przez czwórkę entuzjastów i dysponująca budżetem śmiesznie małym w porównaniu z nawet najmniejszą oficjalną instytucją prywatną lub publiczną, w ciągu roku znalazła się, zdaniem pisma „Obieg”, w setce najważniejszych inicjatyw, wydarzeń, osób i instytucji związanych ze sztuką współczesną w 2010 roku ${ }^{39}$. W tym samym roku Agnieszka Sabor i Piotr Kosiewski na łamach „Tygodnika Powszechnego" uznali ją za jedną z dziesięciu najważniejszych niepublicznych instytucji kultury w Polsce ${ }^{40}$. Rzeczywiście, w Goldexie odbyło się kilka ważnych wydarzeń, które bez wątpienia wniosły coś do kultury, jak chociażby Anty-kongres Kultury w 2009 r., posthumanistyczna wystawa prac psa Pimpka czy wyśmienita redegustacja produktów cukierniczych o przedłużonym terminie ważności grupy Luxus.

Czy model Pi sektora, zgodnie z którym działa Goldex Poldex, jest jednak uniwersalizowalny? W pewnym zakresie tak, trzeba mieć jednak świadomość, że opiera się on na zdiagnozowanej przez Pierre'a Bourdieu zasadzie konwersji kapitałów - niewielkie ilości kapitału materialnego są w nim kompensowane dużymi zasobami innych form kapitału, którymi dysponują członkowie Spółdzielni Goldex Poldex; głównie kapitału symbolicznego — doświadczenia zawodowego i wiedzy zdobytej poza Spółdzielnią — oraz społecznego — kontaktów, znajomości i pozycji w różnego rodzaju środowiskach, co umożliwia im realizację wartościowych projektów przy stosunkowo niewielkich nakładach finansowych. Bez tych zasobów - bo jak pokazał Bourdieu, są to zasoby, tyle

${ }^{38} \mathrm{Na}$ poziomie politycznym logika Pi sektora wpisuje się w ogólny ontologiczny model, który przyjmują tacy filozofowie jak Antonio Negri czy Alain Badiou. Zob. np. M. Hardt, A. Negri, Imperium, tłum. A. Kołbaniuk, S. Ślusarski, Warszawa 2005; A. Badiou, Lêtre et l'événement. Tome 2: Logiques des mondes, Paris 2006. Chociaż pod wieloma względami polemizują ze sobą, obaj zakładają, że istnieje jeden, wspólny świat, w obrębie którego działają zarówno ruchy emancypacyjne, jak i siły establishmentu, a poszukiwanie pozycji poza skazane jest na niepowodzenie polityczne. Więcej pisałem na ten temat w tekście Co jest wywrotowe? („Kultura Współczesna” 2010, nr 2).

39 Zob. Setka „Obiegu”, http://www.obieg.pl/wydarzenie/15954.

40 Zob. A. Sabor, P. Kosiewski, W potowie drogi, „Tygodnik Powszechny”, 1 sierpnia 2010. 
tylko że mają inną formę niż pieniądze czy maszyny — prowadzenie instytucji takiej jak Goldex Poldex byłoby bardzo trudne, jeśli nie w ogóle niemożliwe.

Druga kwestia to ograniczenie podobne do tych, $z$ jakim musi skonfrontować się trzeci sektor: funkcjonowanie w środowisku społecznym kształtowanym przez hegemoniczne reguły akumulacji kapitału. A reguły owe dyktują nie tylko porządek relacji społecznych, ale interweniują już w sam proces konstrukcji podmiotowości, co trafnie ujmuje koncepcja ideologii Louisa Althussera ${ }^{41}$. Jest to podmiotowość indywidualistyczna, konkurencyjna, nastawiona do życia utylitarystycznie, niechętna do dzielenia się i mająca ogromne trudności w realizacji działań grupowych. Więc chociaż teoretycznie można by spekulować, że skoro cztery osoby są $\mathrm{w}$ stanie zrobić tak wiele, ile mogłaby osiągnąć podobna organizacja skupiająca osób 20, 50 albo nawet 100, w praktyce widać, że Goldex Poldex nie ewoluuje w tę stronę. Działa bardziej jak typowa instytucja kultury oparta na modelu animatorzy (kuratorzy, artyści itp.) versus publiczność niż jak partycypacyjna i rozwijająca się wspólnota. Nie jest to zaskakujące. Potwierdza tylko wyrażone wcześniej przekonanie, że problem nowych mechanizmów wytwarzania kultury musi być rozpatrywany łącznie z całością porządku społecznego, w którym kultura ta pojawia się i funkcjonuje.

\section{ON THE FORM OF THE DEMOCRATIC CONTROL OF THE CREATION OF CULTURE}

\section{Summary}

The text deals with various manners of institutionalization in the field of "independent culture". Referring to research undertaken both in Poland and abroad, the author criticizes the NGO model, indicating the commercialization and governamentalization of the third sector. As a result, NGO cultural institutions lose their independence, becoming just new tools for making profits or doing state politics. The professionalisation of the NGOs renders them similar to the first or second sectors and makes it impossible for them to act as incubators of social capital for which they have been praised in social theory from de Tocqueville to Putnam. The author believes these recent developments create dangers not only for independent culture itself, but for the entire society. As an academic (but also an experienced activist in the field of cultural production), the author tries to sketch a possible alternative. He puts forward a thesis that the most important thing to consider is the institutional form of cultural production. He believes reforms should be undertaken in the direction of strengthening the autonomy and self-governance of cultural institutions by their democratization. Referring to both theoretical analyses and practical examples, the author presents a model of participatory democracy as a possible solution for the commercialization and governamentalization of the third sector.

41 Zob. L. Althusser, Ideologie i aparaty ideologiczne państwa, tłum. A. Staroń, „Nowa Krytyka”, http://nowakrytyka.pl/spip.php?article374. 
Key words/słowa kluczowe

independent culture / kultura niezależna; social capital / kapitał społeczny; NGO / trzeci sektor, instytucje pozarządowe; commercialization / komercjalizacja; governamentalization / urządowienie; self-management / samorządność; participatory democracy / demokracja uczestnicząca 